\title{
Induction of the Autoantigen Proliferating Cell Nuclear Antigen in T Lymphocytes by a Mycobacterial Antigen
}

\author{
Hilary M. Haftel, ** Yan Chang, * Robert Hinderer, ${ }^{*}$ Samir M. Hanash, ${ }^{\star}$ and Joseph Holoshitz* \\ Division of Rheumatology, Departments of ${ }^{*}$ Internal Medicine and ${ }^{\ddagger}$ Pediatrics and Communicable Diseases, University of Michigan \\ Medical Center, Ann Arbor, Michigan 48109
}

\begin{abstract}
Mycobacteria have been implicated in the pathogenesis of autoimmunity. To determine the potential effect of mycobacterial antigens on peripheral blood mononuclear cells (PBMC), we analyzed PBMC incubated with the acetoneprecipitable fraction of Mycobacterium tuberculosis (APMT) for changes in cellular protein expression. Two-dimensional gel analysis showed induction of a $36-\mathrm{kD}$ polypeptide identified as proliferating cell nuclear antigen (PCNA), a known autoantigen, after incubation with AP-MT. PCNA plays a role in cell proliferation and is expressed as a late growth regulated factor. However, its synthesis in response to AP-MT was induced as an early event. The early induction of PCNA was regulated at a posttranscriptional level and was restricted to $T$ cells. Treatment of PBMC with known $T$ cell mitogens, namely PHA, anti-CD3 antibodies, and staphylococcal superantigens failed to induce an early PCNA increase. The distinct characteristics of the AP-MT effect on PCNA expression suggest a separate mechanism of induction in response to AP-MT, compared with the late increase observed in response to mitogens. The induction of PCNA in response to mycobacterial antigens may represent a pathogenically relevant mechanism in autoimmunity. $(J$. Clin. Invest. 1994. 94:1365-1372.) Key words: autoimmunity - cell cycle - cell activation - antigen presentation nuclear antigens
\end{abstract}

\section{Introduction}

Proliferating cell nuclear antigen (PCNA) ${ }^{1}$ is a cofactor of DNA polymerase $\delta$ involved in DNA replication and excision repair (1-7). PCNA levels have provided a measure of prolifer-

Hilary M. Haftel and Yan Chang contributed equally to the work contained in this manuscript.

Address correspondence to Joseph Holoshitz, The University of Michigan Specialized Center of Research in Rheumatoid Arthritis, R4550 Kresge I, 200 Zina Pitcher Place, Ann Arbor, MI 48109-0591.

Received for publication 14 March 1994 and in revised form 10 May 1994.

1. Abbreviations used in this paper: AP-MT, acetone-precipitable fraction of Mycobacterium tuberculosis; 2-D PAGE, two-dimensional PAGE; PCNA, proliferating cell nuclear antigen; PE, phycoerythrin; PVDF, polyvinyldifluoride; SEA, staphylococcal enterotoxin A; SEB, staphylococcal enterotoxin B.

J. Clin. Invest.

(c) The American Society for Clinical Investigation, Inc. $0021-9738 / 94 / 10 / 1365 / 08 \quad \$ 2.00$

Volume 94, October 1994, 1365-1372 ative activity and cell cycle progression in a variety of cell populations (8-12). Interestingly, PCNA has also been implicated in autoimmunity. Approximately $3 \%$ of patients with systemic lupus erythematosus express anti-PCNA antibodies (13, 14). The underlying mechanism(s) responsible for antibody formation against certain cellular proteins but not others is unknown.

Mycobacteria have been suggested as potential triggering agents in certain autoimmune conditions. Evidence to that effect includes the high prevalence of antinuclear antibodies, rheumatoid factor, and other autoantibodies in the sera of patients with pulmonary tuberculosis (for review see reference 15), induction of autoimmune arthritis in rats immunized with complete Freund's adjuvant (16), the high incidence of inflammatory arthritis in humans after BCG immunotherapy (17), and the reactivity of synovial fluid and peripheral blood $\mathrm{T}$ lymphocytes from patients with rheumatoid arthritis (RA) to mycobacterial heat shock proteins (18) and to the acetone-precipitable fraction of Mycobacterium tuberculosis (AP-MT) $(19,20)$.

Our previous studies of RA synovial fluid cells have shown that AP-MT selectively activates, and can be used to expand, a subset of $\gamma \delta \mathrm{T}$ cells (21). Proliferation of these cells in response to AP-MT requires a close contact with antigen-presenting cells (22). Presentation of AP-MT to $\gamma \delta$ T cells seems to have distinct characteristics. Unlike presentation of nominal antigens and superantigens, presentation of AP-MT is independent of MHC molecules $(22,23)$.

To better understand the relationship between mycobacteria and autoimmunity, we have investigated the molecular changes that peripheral blood mononuclear cells undergo after their exposure to AP-MT. Here we report that AP-MT, specifically, induced a posttranscriptional upregulation of the autoantigen PCNA in peripheral blood T lymphocytes. Unlike its induction in response to mitogen stimulation, which occurs as a late event during cell cycle progression, induction of PCNA by AP-MT occurred as an early event and was dissociated from cell cycle progression.

\section{Methods}

Antigens and antibodies. AP-MT was prepared from M. tuberculosis strain $\mathrm{H}_{37} \mathrm{Ra}$ (Difco Laboratories, Inc., Detroit, MI) as previously described (19). Staphylococcal enterotoxins A and B (SEA and SEB, respectively) were purchased from Toxin Technology, Inc. (Sarasota, FL). Phytohemagglutinin (PHA) was purchased from Murex Diagnostics (Norcross, GA). The anti-PCNA monoclonal antibodies, 19F4 ( $\mathrm{IgG}_{1}$; Coulter Corp., Hialeah, FL) and PC10 ( $\mathrm{IgG}_{2 \mathrm{a}}$; Boehringer Mannheim Biochemicals, Indianapolis, IN), were used in immunoblots and flow cytometric analysis, respectively. Anti-human actin antibody (HHF35) was purchased from Enzo Biochem Inc. (New York). The anti-CD3 antibody, OKT3 $\left(\operatorname{IgG}_{2 \mathrm{a}}\right)$, was used as ascites prepared from the OKT3 hybridoma purchased from American Type Culture Collection (Rockville, MD). Anti-Leu 4 ( $\left.\mathrm{IgG}_{1}\right)$ was purchased from Becton Dick- 
inson Immunocytometry Systems (Mountain View, CA) and used in flow cytometry in its phycoerythrin (PE)-conjugated form. Isotypematched controls in flow cytometry studies were $\mathrm{MsIgG}_{1}-\mathrm{RD} 1$ (Coulter Corp.) for $\mathrm{IgG}_{1}$ and $\gamma 2 \mathrm{a}$ Pure (Becton Dickinson Immunocytometry Systems) for $\operatorname{IgG}_{2 \mathrm{a}}$. Goat anti-mouse $\mathrm{IgG}_{2 \mathrm{a}}$ conjugated to FITC was purchased from Boehringer Mannheim Biochemicals.

Cell culture. All experiments, unless stated otherwise, were performed in serum-free RPMI 1640 medium containing $1 \%$ Nutridoma HU (Boehringer Mannheim Biochemicals), $10 \mathrm{mM}$ Hepes, $200 \mathrm{mM}$ glutamine, and $1 \%$ penicillin/streptomycin (referred to below as Nutridoma medium). Peripheral blood mononuclear cells (PBMC) were isolated from healthy donors using a Ficoll density-gradient technique. PBMC at concentrations of 3-6 $\times 10^{6} / \mathrm{ml}$ in Nutridoma medium were cultured at $37^{\circ} \mathrm{C}$ in polypropylene tubes for 24 or $48 \mathrm{~h}$. Antigens were added subsequently at different time points to allow stimulation with the tested antigen during the last $1,2,4,24$, or $48 \mathrm{~h}$ of incubation. This method was used to assure identical handling of all samples during the harvesting stage. Identical results were obtained when incubation with the antigens was allowed from the beginning of the culture period. Concentrations of the tested antigens were predetermined in dose-response experiments and included 20-100 $\mu \mathrm{g} / \mathrm{ml}$ AP-MT, 2-10 $\mu \mathrm{g} / \mathrm{ml}$ PHA, $100 \mathrm{ng} / \mathrm{ml}$ SEA or SEB, or 1:100 dilution of OKT3 ascites. At the end of the incubation period, the cells were centrifuged at 6,000 rpm in an Eppendorf microfuge (Eppendorf North America, Inc., Madison, WI), and the supernatant was decanted. Cells were washed three times in Nutridoma medium.

Two-dimensional polyacrylamide gel electrophoresis (2-D PAGE). Cell pellets were lysed in $40 \mu \mathrm{l}$ of a detergent lysate containing $8 \mathrm{M}$ urea, 2\% (vol/vol) Nonidet P-40 surfactant (Hoefer Scientific Instruments, San Francisco, CA), 20 mM ampholytes (pH 3.5-10) (Pharmacia LKB Biotechnology Inc., Piscataway, NJ), 2\% (vol/vol) 2-mercaptoethanol, and $0.2 \mathrm{mM}$ phenylmethylsulfonyl fluoride (Sigma Immunochemicals, St. Louis, MO) in distilled deionized water. 2-D PAGE was performed as described previously (24). $25-\mu \mathrm{l}$ aliquots containing $\sim 70 \mu \mathrm{g}$ of protein were applied to isofocusing gels. First dimension gels contained $50 \mathrm{ml}$ of ampholytes/liter ( $\mathrm{pH} 3.5-10)$. Isofocusing was performed at $1,200 \mathrm{~V}$ for $16 \mathrm{~h}$ and $1,500 \mathrm{~V}$ for the last $2 \mathrm{~h}$. For the second dimension separation, an acrylamide gradient of $11.4-14.0 \%$ was used. Protein spots were visualized by a silver-staining technique (25). Quantification of spots on silver-stained gels was performed as described previously (26). Each gel was scanned in a $1,024 \times 1,024$ pixel format, with $160 \mu \mathrm{m}$ as the pixel width. All gel images were digitized and analyzed. The integrated intensities of PCNA and seven other reference proteins were measured in units of optical density times square millimeter. The reference spots were used to adjust for gel-togel variation in staining or amount of protein loaded (26). Data were analyzed using the Michigan Interactive Data Analysis System statistical package (27).

$\left.{ }^{35} S\right]$ Methionine incorporation studies. To assess the extent of protein synthesis, $\left[{ }^{35} \mathrm{~S}\right]$ methionine incorporation studies were performed. PBMC were incubated with AP-MT or PHA in methionine-free Nutridoma medium over a time course as described above. $\left[{ }^{35} \mathrm{~S}\right]$ Methionine (Amersham Corp., Arlington Heights, IL), $200 \mu \mathrm{Ci}$ per $5 \times 10^{6}$ cells, was added for the final $3 \mathrm{~h}$ of incubation. The cells were washed, lysed, and resolved by 2-D PAGE as described above. The proteins in the gels were then electrophoretically transferred to Immobilon-P polyvinyldifluoride (PVDF) membranes (Millipore Corp., Bedford, MA). Filter papers were soaked in $100 \%$ methanol and immersed in either anode transfer buffer ( $50 \mathrm{mM}$ boric acid and $20 \%$ methanol, adjusted to $\mathrm{pH}$ 9.0 with sodium hydroxide) or cathode buffer (as above, with $5 \%$ methanol). Electrotransfer was performed for $2 \mathrm{~h}$ at a current of 0.15 $\mathrm{mA} / \mathrm{cm}^{2}$. Membranes were then exposed to storage phosphor imaging plates (Molecular Dynamics, Inc., Sunnyvale, CA) for $48 \mathrm{~h}$. Digitized images were obtained using a PhosphorImager system (Molecular Dynamics, Inc.) as described (28). The relative position of the spots detected was compared with the position of the polypeptides identified by silver stain and immunoblot (29). Individual spots were quantitated using ImageQuant software (Molecular Dynamics, Inc.). Results are expressed as PhosphorImager signal per hours of exposure.

Immunoblots. Cell pellets were lysed, and proteins were resolved by 2-D PAGE. Samples were prepared as described (30) with some modifications: after protein transfer to Immobilon-P PVDF, membranes were placed in a blocking solution containing 5\% nonfat milk and $0.02 \%$ sodium azide and $0.02 \%$ Tween 20 (Sigma Immunochemicals) in PBS ( $\mathrm{pH}$ 7.4) for $4 \mathrm{~h}$ to equilibrate the membrane and to block unbound sites. The membranes were then transferred to a fresh blocking solution containing a mixture of anti-PCNA antibody $19 \mathrm{~F} 4$ and antiactin antibody HHF35, both at a concentration of $5 \mu \mathrm{g} / \mathrm{ml}$, and incubated overnight at $4^{\circ} \mathrm{C}$. The membranes were washed twice in PBS and once in blocking solution and incubated for $4 \mathrm{~h}$ with ${ }^{125} \mathrm{I}$-labeled sheep anti-mouse IgG (Dupont/New England Nuclear, Boston, MA) diluted 1:1,000 in PBS. Membranes were then exposed to storage phosphor imaging plates for $48 \mathrm{~h}$ and analyzed as described above.

Northern blot analyses. Northern blot analysis was performed as described previously (31). PBMC were stimulated with AP-MT in Nutridoma medium. Cell aliquots were harvested, and total cellular RNA was prepared by the RNAzol ${ }^{\mathrm{TM}}$ B method (Cinna Scientific, Inc., Friendswood, TX) as described (32). Total cellular RNA was also prepared from Jurkat cells as a positive control. The purified RNA was dissolved in diethyl pyrocarbonate-treated $0.5 \%$ SDS and quantitated by spectrophotometry as well as a quantitative agarose gel. Equal amounts of RNA were denatured in formaldehyde and formamide, followed by fractionation on a $1 \%$ agarose formaldehyde gel and transferred to Magna Graph NT membranes (Westboro, MA). The filters were hybridized to an $\left[\alpha{ }^{32} \mathrm{P}\right] \mathrm{dCTP}$ nick translated 1.2-kb HindIII/ BamHI human PCNA cDNA probe (donated by Dr. Eng Tan, Scripps Clinics, La Jolla, CA) as described (33). After overnight hybridization, the membranes were washed in high stringency conditions, air-dried, and visualized by PhosphorImager (28). The membranes were stripped and rehybridized with a 1.4-kb PstI-digested human HLA B7 cDNA probe (donated by Dr. David Fox, University of Michigan, Ann Arbor, MI) as an internal control to assure equal RNA loading.

Flow cytometry and cell cycle analysis. PBMC were stimulated with AP-MT or PHA as described above. The cells were washed twice in PBS containing 1\% FCS (Gibco Laboratories, Grand Island, NY) and incubated for 30 min with normal mouse serum (Sigma Immunochemicals), diluted 1:5, to block nonspecific binding sites. The cells were washed again twice in 1\% FCS/PBS and subsequently incubated for 30 min with either anti-CD3 monoclonal antibody conjugated to PE (Leu-4-PE; Becton Dickinson Immunocytometry Systems) or a PEconjugated mouse $\mathrm{IgG}_{1}$ (MsIgG $\mathrm{RD1}$; Coulter Corp.) as an isotypematched control. To obtain intranuclear staining, cells were permeabilized by Triton X (34) as follows: each sample was washed twice in $1 \%$ FCS/PBS and then fixed with $1 \%$ paraformaldehyde for $20 \mathrm{~min}$ on ice and permeabilized with $1 \mathrm{ml} 0.1 \%$ Triton X-100 (Sigma Immunochemicals) as described (34). After permeabilization, the cells were washed in $1 \%$ FCS/PBS and subsequently incubated for $30 \mathrm{~min}$ with either the anti-PCNA monoclonal antibody PC10 or control monoclonal $\mathrm{IgG}_{2 \mathrm{a}}$ ( $\gamma 2 \mathrm{a}$ Pure; Becton Dickinson Immunocytometry Systems). The samples were washed twice in $1 \%$ FCS/PBS and incubated for $30 \mathrm{~min}$ with FITC-conjugated goat anti-mouse $\operatorname{IgG}_{2 \mathrm{a}}$ (Boehringer Mannheim Biochemicals). The cells were washed, resuspended in $1 \%$ FCS/PBS, and analyzed by flow cytometry using an EPICS-C flow cytometer and the QuadStat statistical package (Coulter Corp.).

For cell cycle analysis, fresh PBMC were cultured for $48 \mathrm{~h}$ in $10 \%$ FCS in RPMI 1640 in the presence or absence of $10 \mu \mathrm{M}$ hydroxyurea (Sigma Immunochemicals). The cells were then washed and resuspended in Nutridoma medium with or without $10 \mu \mathrm{M}$ hydroxyurea and stimulated with AP-MT or PHA over time. Samples were then washed, permeabilized with $70 \%$ ice-cold ethanol, and kept overnight at $4^{\circ} \mathrm{C}$. The cells were either stained for PCNA as described above or incubated at room temperature with $40 \mu \mathrm{g} / \mathrm{ml}$ RNase A for $30 \mathrm{~min}$, followed by the addition of $18 \mu \mathrm{g} / \mathrm{ml}$ propidium iodide (both from Sigma Immunochemicals). Cells were again incubated at room temperature for $30 \mathrm{~min}$ and then for $30 \mathrm{~min}$ at $4^{\circ} \mathrm{C}$. Analysis of DNA content and PCNA 
fluorescence was performed using an EPICS elite flow cytometer (Coulter Corp.). Cell cycle distribution data were computed with MultiCycle software from Phoenix Flow Systems (San Diego, CA).

\section{Results}

Induction of PCNA in PBMC stimulated with AP-MT. Freshly isolated PBMC were stimulated with AP-MT and harvested at different time points. 2-D gel analysis showed that a $36-\mathrm{kD}$ protein with a pI of 4.4 was markedly increased as early as 2 h after stimulation with AP-MT (Fig. 1, $A$ and $B$ ). A similar increase was present in cell samples from all healthy individuals tested to date (a total of 21 different donors). Quantitative analysis of the $36-\mathrm{kD}$ polypeptide spot performed on nine individuals showed a mean 10.9-fold increase in the integrated intensity of the protein spot after $4 \mathrm{~h}$ of stimulation with AP-MT, from an integrated intensity of $0.11 \pm 0.07$ to $1.2 \pm 0.18$. Such an increase in spot intensity correlates with a $\sim 30$-fold increase in protein quantity based on prior quantitative measurements of 2-D gels (26). The location of the $36-\mathrm{kD}$ polypeptide in relation to other landmarks in 2-D gels was characteristic of PCNA (27).

To confirm the identity of the $36-\mathrm{kD}$ protein, we performed Western blot analysis. 2-D gels were transferred to Immobilon$P$ PVDF membranes and stained with a mixture of two monoclonal antibodies, an anti-PCNA antibody and an antiactin antibody, for reference. Fig. 2 shows positive staining at the expected location of PCNA. This immunoblot was overlaid on a $\left[{ }^{35} \mathrm{~S}\right]$ methionine-labeled gel of PBMC stimulated with AP-MT, identifying the induced protein as PCNA. Quantification of the PCNA spot on the immunoblot demonstrated an increase in its intensity after $2 \mathrm{~h}$ of stimulation with AP-MT from 1980 to 7915 phosphor signals $/ \mathrm{h}$.

The early increase in PCNA occurs in T cells and is specific for AP-MT. To identify the subpopulation of PBMC in which PCNA is induced, two-color flow cytometry analysis was performed. Cells were first stained with an anti-CD3 antibody, followed by permeabilization and intranuclear staining with an anti-PCNA antibody. The double staining approach allowed us to compare PCNA levels in the $\mathrm{CD}^{+}$and the $\mathrm{CD}^{-}$subsets. A representative experiment (one of eight repetitions) is shown in Fig. $3 \mathrm{~A}$. Only the $\mathrm{CD}^{+}$population showed an early increase in PCNA staining after AP-MT stimulation (Fig. $3 A$ ). The increment in the percentage of cells expressing PCNA over time in each subset is plotted in Fig. $3 \cdot B$. While a significant increase in the percentage of $T$ cells showing positive staining with antiPCNA antibody could be detected $1 \mathrm{~h}$ after stimulation with AP-MT, no comparable increase in staining in the $\mathrm{CD}^{-}$cell population was seen. The mean percent increase of PCNApositive $\mathrm{CD}^{+}$cells at $4 \mathrm{~h}$ in eight consecutive experiments was $11.1 \pm 3.5$, compared with $1.1 \pm 0.3$ in the $\mathrm{CD}^{-}$population $(P<0.001)$. In addition, two-color flow cytometry experiments using antimonocyte and anti-B cell antibodies showed no increase in PCNA positivity at the early time points in those subsets (data not shown). Thus, we conclude that the early PCNA increase observed in PBMC is contributed primarily by $T$ cells

To determine the antigenic specificity of the early increase in PCNA protein, PBMC were stimulated with several known T cell mitogens. As shown in Fig. 4, neither PHA, OKT3, SEA, nor SEB resulted in an early increase in PCNA. As expected, however, the PHA, OKT3, and SEA did induce a late increase in PCNA at 24-48 $\mathrm{h}$ (Fig. 4).

The mechanism for the early increase in PCNA. Previous studies have shown that expression of PCNA in proliferating cells is regulated by both transcriptional and posttranscriptional mechanisms (33-36). As shown in Fig. 5, an increase in PCNA, based on uptake of radiolabeled methionine, could be detected within $1 \mathrm{~h}$ after incubation of PBMC with AP-MT, indicating de novo synthesis of PCNA. To determine whether the increase in PCNA at the protein level was paralleled by an increase in PCNA mRNA, we performed Northern blot analysis. There was no detectable increase in PCNA mRNA expression at the early time points (Fig. 6). Furthermore, actinomycin D had no effect on early PCNA synthesis (Fig. 7). There was no significant decrease in radiolabeled methionine incorporation into PCNA at the early time points in the presence of actinomycin D. There was, however, complete inhibition at $24 \mathrm{~h}$. Taken together, these results suggest that the early induction of PCNA protein in response to AP-MT occurs as a posttranscriptional event, whereas the late increase is regulated primarily at the level of transcription.

The early increase in PCNA is independent of cell cycle progression. Previous studies of cells induced to proliferate have shown that PCNA protein expression is induced during the G1/S transition and peaks in the S phase of the cell cycle $(1,9,11)$. To determine whether the early induction of PCNA observed in response to AP-MT correlates with G1/S transition, cell cycle analysis after AP-MT stimulation was undertaken. As can be seen in Fig. 8, the AP-MT-induced early increase in PCNA expression was not accompanied by cell cycle progression from $\mathrm{G} 1$ to $\mathrm{S}$ phase. Treatment with hydroxyurea to induce cell cycle arrest did not prevent the early increase in PCNA in response to AP-MT (data not shown).

\section{Discussion}

Our data show that stimulation with a mycobacterial extract results in early induction of PCNA protein in T lymphocytes. This rapid induction occurs in response to AP-MT, but not in response to mitogens that induce PCNA late during progression through the cell cycle. The early increase in PCNA occurs by a posttranscriptional mechanism.

The significance of these findings is fourfold. First, this is the first report implicating a microbial antigen in the induction of a known autoantigen, PCNA. Second, the mechanism of induction is distinct from that of known mitogens. Third, induction of PCNA by AP-MT is not accompanied by cell cycle progression. Fourth, our findings may provide important clues about the relationship between mycobacteria and autoimmunity.

Our flow cytometry data indicate that the early increase of PCNA in PBMC occurs in T cells. Previous studies have shown that PCNA can be induced by $\mathrm{T}$ cell mitogens as a late event during cell cycle progression. A $20 \%$ increase in PCNA protein has been demonstrated by immunofluorescence in peripheral blood lymphocytes stimulated for $72 \mathrm{~h}$ with PHA, pokeweed mitogen, or concanavalin A (13). Similarly, a PHA-induced PCNA mRNA synthesis was detected after $48 \mathrm{~h}$ of stimulation (37). T lymphocytes stimulated with anti-CD3 antibody and exogenous IL-2 displayed an increase in PCNA levels only after $20 \mathrm{~h}$, peaking at $48 \mathrm{~h} \mathrm{(38)}$. Our finding that known $\mathrm{T}$ cell mitogens, such as PHA, anti-CD3 antibodies, and staphylococcal superantigens, do not cause an increase in PCNA until 

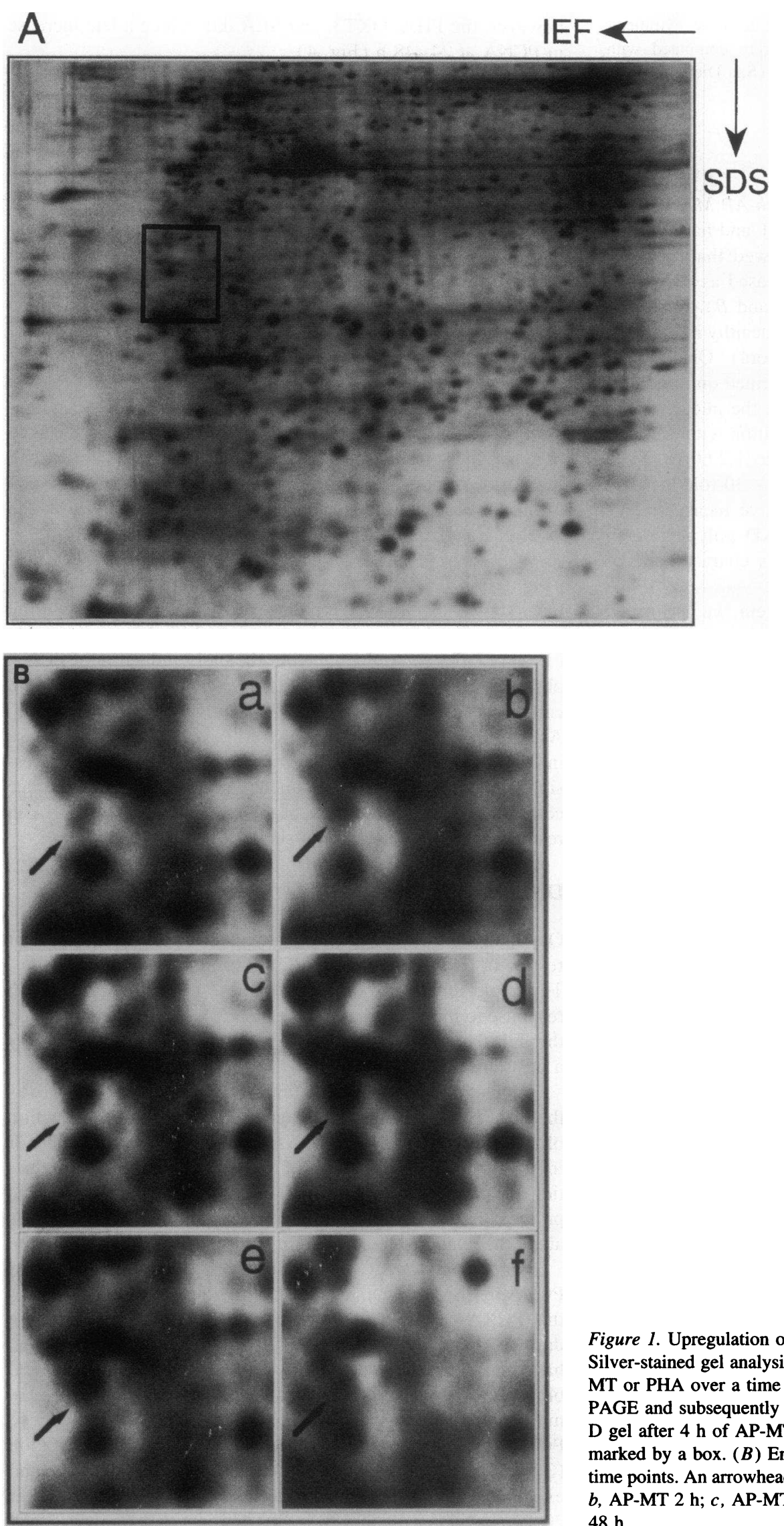

Figure 1. Upregulation of a $36-\mathrm{kD}$ protein upon AP-MT stimulation. Silver-stained gel analysis. Five million PBMC were incubated with APMT or PHA over a time course. Cellular proteins were resolved by 2-D PAGE and subsequently silver-stained. $(A)$ A representative full-size 2$D$ gel after $4 \mathrm{~h}$ of AP-MT stimulation is shown. The area of interest is marked by a box. $(B)$ Enlarged sections of the relevant area in different time points. An arrowhead indicates the $36-\mathrm{kD}$ protein spot. $a$, no antigen; $b$, AP-MT $2 \mathrm{~h} ; c$, AP-MT $4 \mathrm{~h} ; d$, AP-MT 24 h; $e$, AP-MT 48 h; $f$, PHA $48 \mathrm{~h}$. 


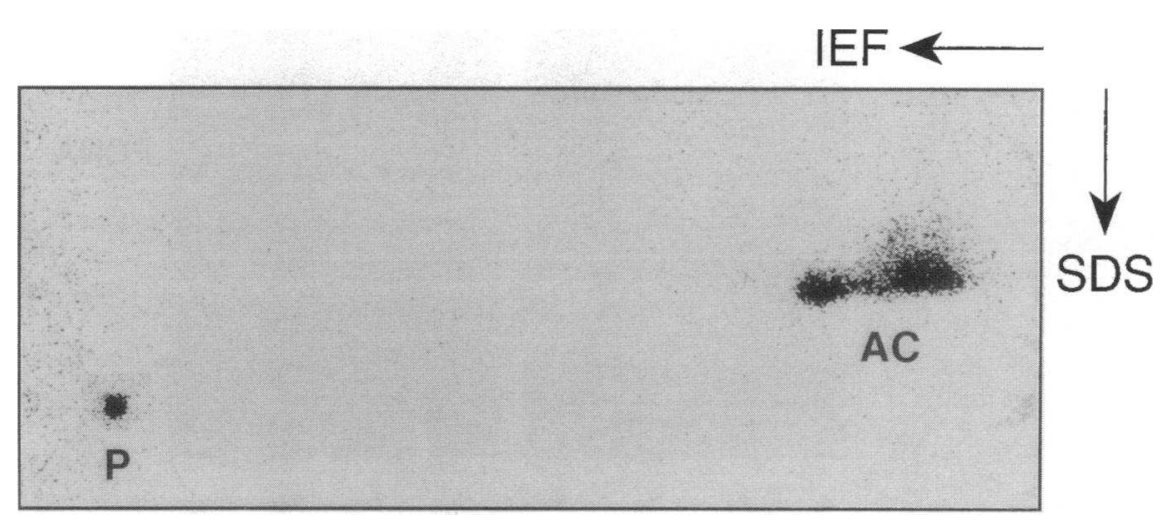

Figure 2. Identification of the $36-\mathrm{kD}$ upregulated protein as PCNA. Western blot analysis PBMC were incubated with or without APMT as described in Methods. Cellular proteins were resolved by 2-D PAGE and transferred to Immobilon-P PVDF membranes. The membranes were stained with antiPCNA and antiactin monoclonal antibodies, followed by ${ }^{125} \mathrm{I}$-labeled sheep anti-mouse IgG, and exposed to storage phosphor imaging plates. The spot labeled $A C$ identifies actin with a molecular mass of $43 \mathrm{kD}$ and a pI of 5.2. The protein spot labeled $P$ identifies PCNA with a molecular mass of $36 \mathrm{kD}$ and a pI of 4.4 .

24-48 $\mathrm{h}$ after stimulation concurs with previous studies and is in contrast with the rapid induction observed in response to AP-MT.

Although the data presented here clearly identify $\mathrm{T}$ lymphocytes as the source of the increased PCNA, it is noteworthy that purified T cells cultured with AP-MT fail to show an increased expression of this protein. Cell mixing experiments using purified subsets of PBMC reveal that the early induction of PCNA in $T$ cells requires the presence of monocytes (Haftel, H. M., S. M. Hanash, and J. Holoshitz, unpublished data). This observation suggests that antigen presentation is required. Experiments to address the relative role of cell contact versus cytokines and identification of the subpopulations of $T$ cells in which PCNA is preferentially induced (e.g., $\mathrm{CD}^{+}{ }^{+}$versus $\mathrm{CD}^{+}$,

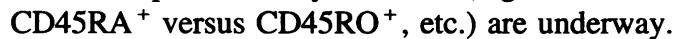

Induction of PCNA has been described in several other systems. Human breast epithelial cultures stimulated with a variety of growth factors, including epidermal growth factor, transforming growth factor- $\alpha$, or a combination of insulin/hydrocortisone/cholera toxin, showed increased PCNA protein only after 48 h (39). Similar studies with quiescent mouse 3T3 cells showed no increase in the protein after the addition of serum, platelet-derived growth factor, or fibroblast growth factor until 8-12 $\mathrm{h}$ after stimulation (40). Studies using an IL-2-dependent $\mathrm{T}$ cell line demonstrated an increase in PCNA mRNA within 4$8 \mathrm{~h}$ of IL-2 stimulation, but synthesis did not become maximal until $24-28 \mathrm{~h}$ after stimulation (41). It is unlikely that IL-2 is the mediator for the induction of PCNA in response to AP-MT, as peripheral blood $\mathrm{T}$ lymphocytes, unlike cloned $\mathrm{T}$ cell lines, express very low levels of IL-2 receptors. In addition, PBMC cultured with AP-MT do not produce any detectable IL-2. Recombinant human IL-2, even in superphysiologic concentrations, failed to increase PCNA protein expression in PBMC before 24 h of stimulation (Haftel, H. M., S. M. Hanash, and J. Holoshitz, unpublished data).
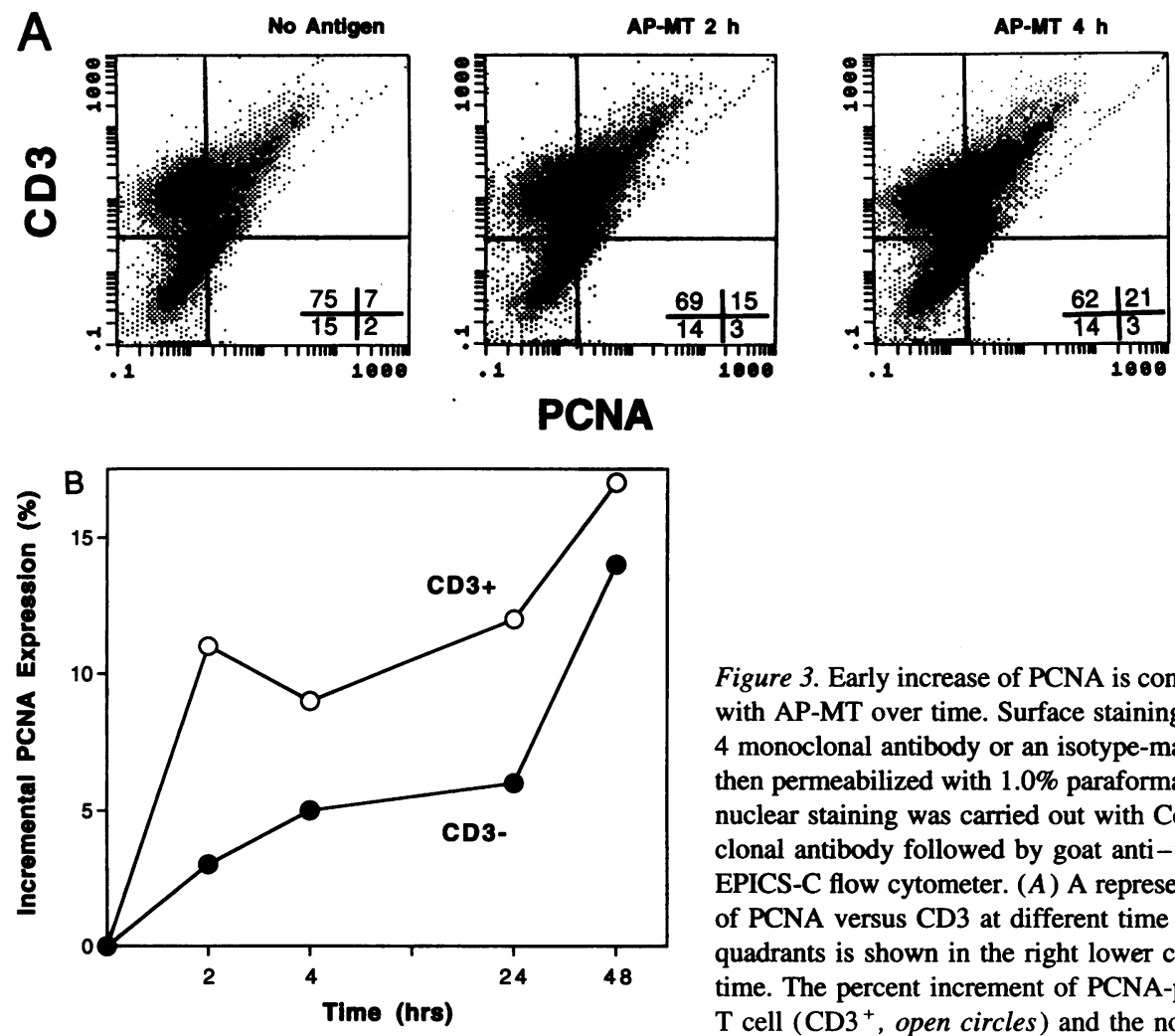

Figure 3. Early increase of PCNA is confined to T lymphocytes. PBMC were stimulated with AP-MT over time. Surface staining was performed with PE-conjugated anti-Leu4 monoclonal antibody or an isotype-matched monoclonal antibody control. Cells were then permeabilized with $1.0 \%$ paraformaldehyde followed by $0.1 \%$ Triton X-100. Intranuclear staining was carried out with Coulter clone PC10 anti-PCNA or control monoclonal antibody followed by goat anti-mouse $\mathrm{IgG}_{2 \mathrm{a}}-\mathrm{FITC}$ and analyzed by a Coulter EPICS-C flow cytometer. ( $A$ ) A representative experiment of two-color flow cytometry of PCNA versus CD3 at different time points. Percentage of cells in each of the four quadrants is shown in the right lower corners. $(B)$ Change in PCNA expression over time. The percent increment of PCNA-positive cells was calculated separately for the $\mathrm{T}$ cell $\left(\mathrm{CD}^{+}{ }^{+}\right.$, open circles $)$and the non- $\mathrm{T}$ cell $\left(\mathrm{CD}^{-}{ }^{-}\right.$, closed circles $)$populations. 


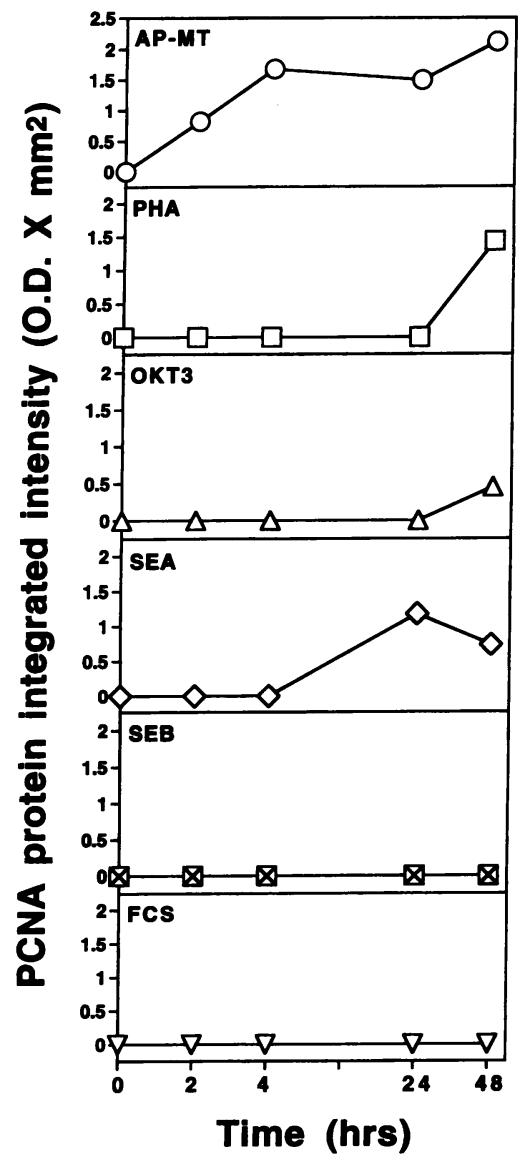

Figure 4. Early induction of PCNA is specific for AP-MT. PBMC were incubated over time with either AP-MT (circles), PHA (squares), OKT3 (triangles), SEA (diamonds), SEB (crossed boxes), or 10\% FCS (inverted triangles). Cellular proteins were resolved by 2-D PAGE, silver stained, and PCNA quantitated. Protein integrated intensity is expressed in units of optical density times square millimeter.
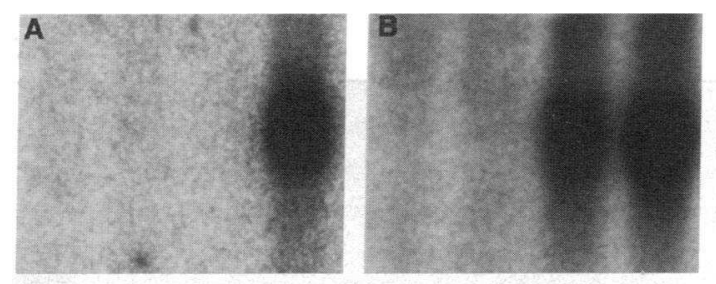

PCNA
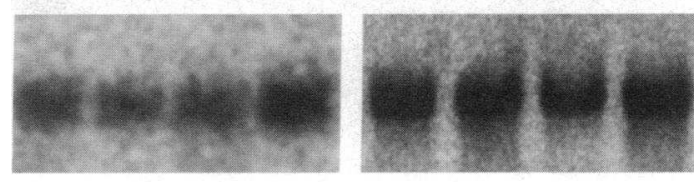

HLA

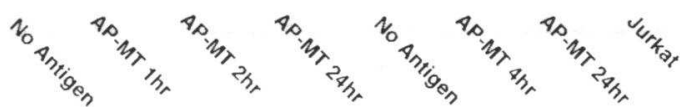

Figure 6. Northern blot analysis. Total RNA was isolated from PBMC incubated in the presence or absence of AP-MT. Equal amounts of RNA from each fraction were separated on a $1 \%$ agarose gel and transferred to Immobilon PVDF membrane. The membranes were hybridized with PCNA cDNA and HLA B7 cDNA probes. The Jurkat cell line was used as a positive control. $A$ and $B$ depict two representative experiments.

The nature of the bioactive component of AP-MT is currently unknown. Preliminary results indicate that a mannosecontaining low molecular weight antigen is present in AP-MT $(42,43$, and our unpublished data). It is unlikely that LPS accounts for the bioactivity reported here, since there is no detectable endotoxin activity in AP-MT, and incubation of PBMC with purified mycobacterial LPS did not result in increased expression of PCNA. Purified mycobacterial $65-\mathrm{kD}$ heat shock protein, likewise, did not induce PCNA (Haftel, H. M., S. M. Hanash, and J. Holoshitz, unpublished data).

The kinetics of PCNA induction in response to AP-MT relative to other inducers of PCNA suggests that a different signaling pathway may be responsible for induction in response to AP-MT compared with induction in response to known mitogens. Alternatively, it is possible that AP-MT activates the same

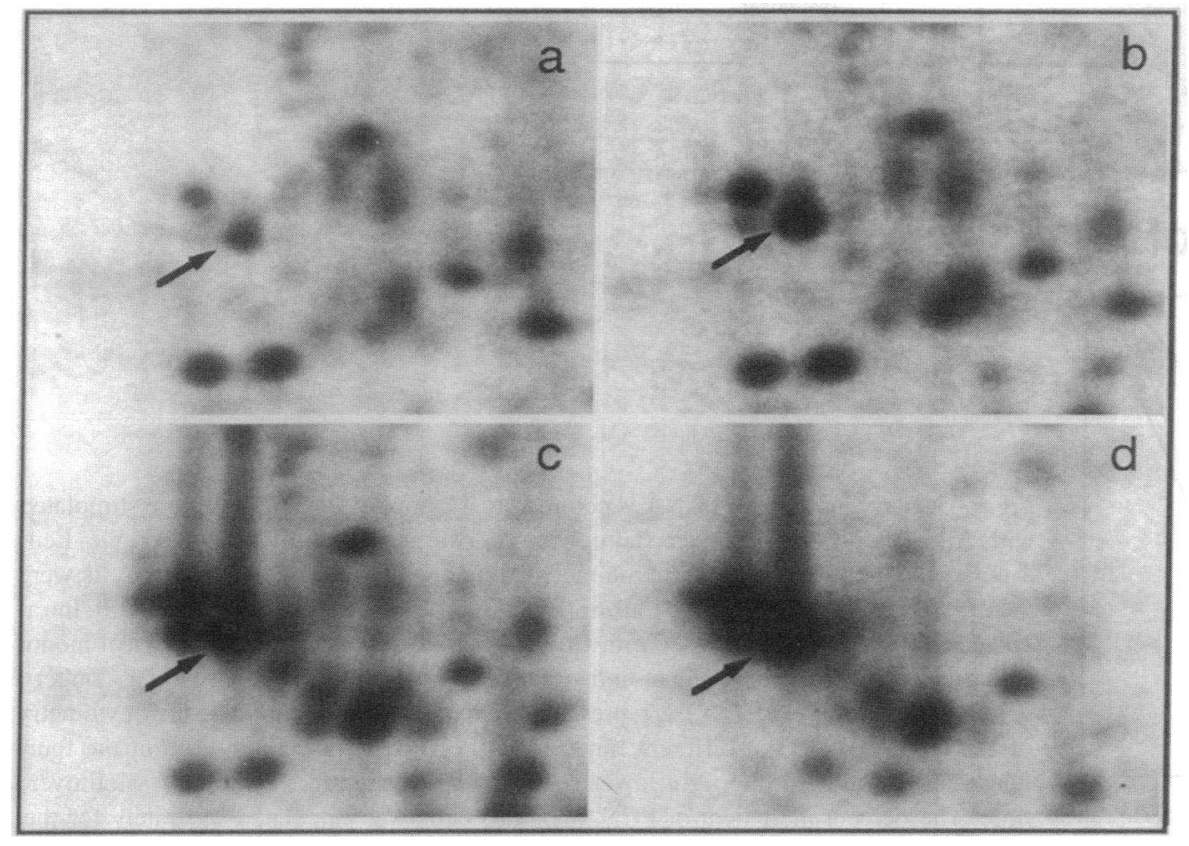

Figure 5. Early upregulation of PCNA involves de novo protein synthesis. PBMC were incubated in the presence or absence of AP-MT in methionine-free Nutridoma medium. $\left[{ }^{35}\right.$ S $]$ Methionine was added for the final $3 \mathrm{~h}$ of incubation. Cellular proteins were resolved by 2-D PAGE and exposed to phosphor imaging plates. An arrow points at PCNA. $a$, no antigen; $b$, AP-MT $1 \mathrm{~h} ; c$, APMT 4 h; $d$, AP-MT $24 \mathrm{~h}$. 


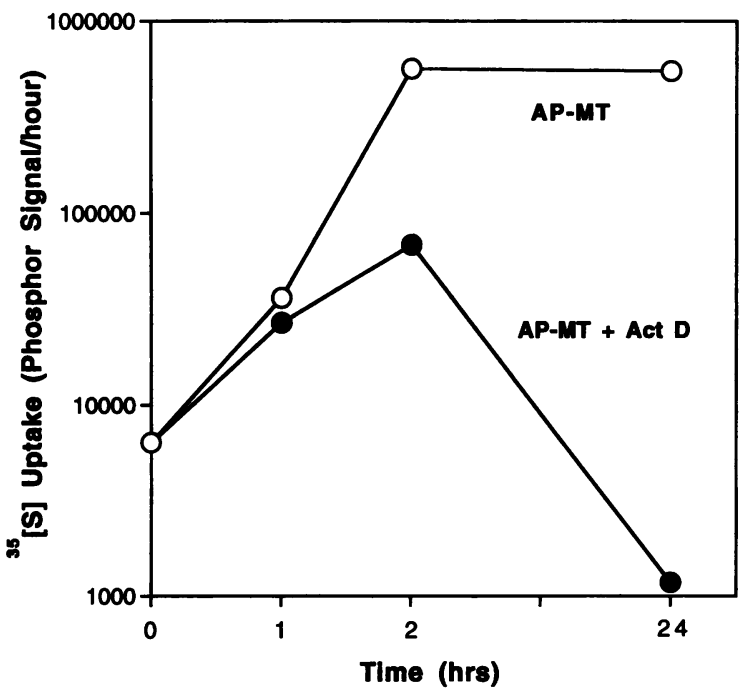

Figure 7. Actinomycin D does not inhibit early upregulation of PCNA. PBMC were incubated with AP-MT over time, and $\left[{ }^{35} S\right]$ methionine incorporation into PCNA was determined in the presence (closed circles) or absence (open circles) of $1 \mu \mathrm{g} / \mathrm{ml}$ of actinomycin D. Cellular proteins were resolved on 2-D PAGE, and $\left[{ }^{35} \mathrm{~S}\right]$ methionine incorporation in PCNA was quantitated and expressed as phosphor signal per $h$.

pathway, albeit more efficiently. The fact that AP-MT-induced PCNA induction was not only different temporally but did not lead to cell cycle progression may indicate that a distinct pathway is involved.

The association of PCNA expression with cell cycle progression in proliferating cells has been studied previously (10, $12,13,29,44)$. PCNA levels increase in late G1 and peak during $S$ phase and diminish in $\operatorname{G2} / \mathrm{M}(1,11,9,45)$. This increase has been shown to be most noticeable in cells that have been previously resting, although spontaneously proliferating cells have been shown to exhibit a two- to threefold increase in PCNA during the $S$ phase (46). The expression of PCNA has also been shown to be linked to DNA synthesis. Changes in the nuclear distribution of PCNA to sites of DNA synthesis appear to be dependent on DNA replication (47). It has been shown, however, that although DNA synthesis requires PCNA expression $(3-5,7,48)$, PCNA can be expressed in the presence of DNA synthesis inhibitors $(33,42,49)$. It is therefore conceivable that an increase in PCNA could occur independent of DNA synthesis and that the regulation of this protein could be dissociated from the regulation of other DNA synthesisrelated factors. Our data are consistent with this possibility.

Another significant finding is that the early increase in PCNA was regulated by a posttranscriptional mechanism. Some previous studies of proliferating cells have shown that PCNA expression is regulated at the level of transcription $(33,35)$. Others have demonstrated a role for both transcriptional and posttranscriptional mechanisms. Increased PCNA mRNA stability after antigen stimulation has been found in 3T3 cells transfected with the human PCNA cDNA (36) and in a cloned murine $T$ helper cell line (34). Our results with actinomycin D (Fig. 7) indicate that inhibition of transcription has no effect on the early synthesis of PCNA protein, although a complete inhibition was found at $24 \mathrm{~h}$. Thus, the early and late induction of PCNA differ not only in their kinetics but also in their regula-

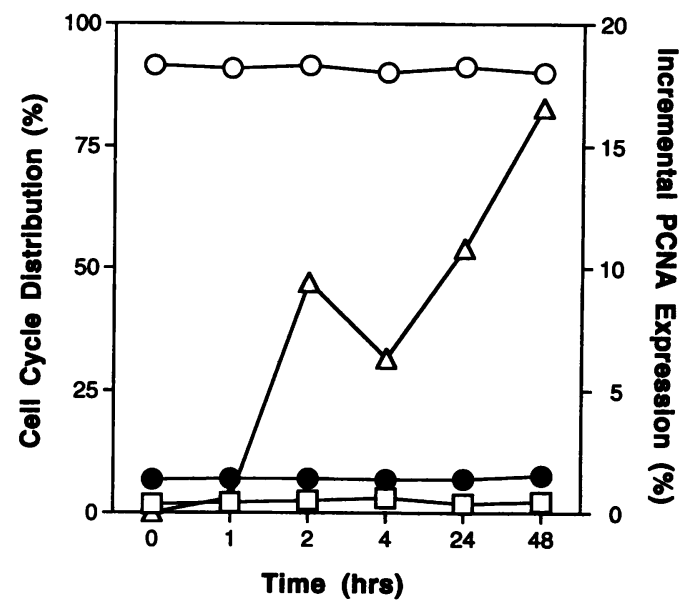

Figure 8. AP-MT-induced PCNA increase is independent of G1/S switch. PBMC were stimulated for various times with AP-MT. Cells were analyzed for PCNA positivity and DNA content by a Coulter EPICS Elite flow cytometer as described in Methods. Percentages of cells in G0/G1 (open circles), in S phase (closed circles), and in G2 (open squares) are shown vis a vis the incremental percentage of cells with positive PCNA expression (open triangles).

tion. It has been shown recently that PCNA facilitates DNA excision repair without prior synthesis of new PCNA mRNA $(6,7)$. In those studies, however, it was demonstrated that the enhanced repair activity was mediated by a protein which was derived from a previously synthesized pool. This mode of functional upregulation is unlikely to play a role here, since we show that de novo protein synthesis dominates the early PCNA increase.

The relevance of our findings to autoimmunity is presently unknown. Experiments are underway to compare the levels of PCNA in response to AP-MT in cells from patients with autoimmune conditions with that of normal controls. It is noteworthy that a relationship between PCNA levels and autoreactivity was postulated recently, based on dissociation of PCNA levels from cell cycle progression. Turka et al. (50) reported that immature $\mathrm{CD}^{+} \mathrm{CD}^{+}$thymocytes express high levels of PCNA protein and mRNA, relative to mature single positive thymocytes or peripheral blood $\mathrm{T}$ lymphocytes, in the absence of cell cycle progression. It was hypothesized that the level of PCNA expression may play a role in clonal deletion of potentially autoreactive $\mathrm{T}$ cells in the thymus. Since mycobacterial antigens have been implicated in autoimmunity (15-21) and PCNA is a known autoantigen $(13,14)$, it is tempting to speculate that the early increase of PCNA levels in peripheral blood T lymphocytes induced by AP-MT may represent a pathogenically relevant cellular event in autoimmunity.

\section{Acknowledgments}

We thank Rork Kuick for his technical assistance in the digitization and quantification of the 2-D PAGE gels.

This study was supported by grants AR-40544, AR-41703, AR20557, and AR-08220 from the National Institutes of Health and grants from The Arthritis Foundation and The Searle Scholar Program/Chicago Community Trust. 


\section{References}

1. Bravo, R., R. Frank, P. A. Blundell, and H. MacDonald-Bravo. 1987. Cyclin/PCNA is the auxiliary protein of DNA polymerase- $\delta$. Nature (Lond.). 326:515-517.

2. Prelich, G., C. K. Tan, M. Kostura, M. B. Mathews, A. G. So, K. M. Downey, and B. Stillman. 1987. Functional identity of proliferating cell nuclear antigen and a DNA polymerase- $\delta$ auxiliary protein. Nature (Lond.). 326:517520.

3. Prelich, G., M. Kostura, D. R. Marshak, M. B. Mathews, and B. Stillman. 1987. The cell-cycle regulated proliferating cell nuclear antigen is required for SV40 DNA replication in vitro. Nature (Lond.). 326:471-475.

4. Prelich, G., and B. Stillman. 1988. Coordinating leading and lagging strand synthesis during SV40 DNA replication in vitro requires PCNA. Cell. 53:117126.

5. Jaskulski, D., J. K. DeRiel, W. E. Mercer, B. Calabretta, and R. Baserga. 1988. Inhibition of cellular proliferation by antisense oligodeoxynucleotides to PCNA cyclin. Science (Wash. DC). 240:1544-1546.

6. Toschi, L., and R. Bravo. 1988. Changes in cyclin/proliferating cell nuclear antigen distribution during DNA repair synthesis. J. Cell Biol. 107:1623-1628.

7. Shivji, M. K. K., M. K. Kenny, and R. D. Wood. 1992. Proliferating cell nuclear antigen is required for DNA excision repair. Cell. 69:367-374.

8. Bravo, R., S. J. Fey, J. Bellatin, P. M. Larsen, J. Arevalo, and J. E. Celis. 1981. Identification of a nuclear and of a cytoplasmic polypeptide whose relative proportions are sensitive to changes in the rate of cell proliferation. Exp. Cell Res. 136:311-319.

9. Takasaki, Y., J. Deng, and E. M. Tan. 1981. A nuclear antigen associated with cell proliferation and blast transformation. J. Exp. Med. 154:1899-1909.

10. Mathews, M. B., R. M. Bernstein, B. R. Franza, and J. I. Garrels. 1984. Identity of the proliferating cell nuclear antigen and cyclin. Nature (Lond.). 309:374-376.

11. Celis, J. E., and A. Celis. 1985. Cell cycle-dependent variations in the distribution of the nuclear protein cyclin proliferating cell nuclear antigen in cultured cells: subdivision of S phase. Proc. Natl. Acad. Sci. USA. 82:3262-3266.

12. Shipman, P. M., D. E. Sabath, A. H. Fischer, P. G. Comber, K. Sullivan,

E. M. Tan, and M. B. Prystowsky. 1988. Cyclin mRNA and protein expression in recombinant interleukin 2-stimulated cloned murine T lymphocytes. J. Cell. Biochem. 38:189-198

13. Miyachi, K., M. J. Fritzler, and E. M. Tan. 1978. Autoantibody to a nuclear antigen in proliferating cells. J. Immunol. 121:2228-2234.

14. Asero, R., L. Origgi, S. Crespi, E. Bertetti, P. D'Agostino, and P. Riboldi. 1987. Autoantibody to proliferating cell nuclear antigen (PCNA) in SLE: a clinical and serological study. Clin. Exp. Rheumatol. 5:241-246.

15. Shoenfeld, Y., and D. A. Isenberg. 1988. Mycobacteria and autoimmunity. Immunol. Today. 9:178-182.

16. Pearson, C. M. 1956. Development of arthritis, periarthritis, and periostitis in rats given adjuvant. Proc. Soc. Exp. Biol. Med. 91:95-101.

17. Torisu, M., T. Miyahara, N. Shinohara, K. Ohsato, and H. Sonozaki. 1978. A new side effect of BCG immunotherapy: BCG-induced arthritis in man. Cancer Immunol. Immunother. 5:77-83.

18. Res, P. C. M., C. G. Schaar, F. C. Breedveld, W. van Eden, J. D. A. van Embden, I. R. Cohen, and R. R. P. de Vries. 1988. Synovial fluid T cell reactivity against $65 \mathrm{kD}$ heat shock protein of mycobacteria in early chronic arthritis. Lancet. ii:478-480.

19. Holoshitz, J., A. Klajman, I. Drucker, Z. Lapidot, A. Yaretzky, A. Frenkel, W. van Eden, and I. R. Cohen. 1986. T lymphocytes of rheumatoid arthritis patients show augmented reactivity to a fraction of mycobacteria cross-reactive with cartilage. Lancet. ii:305-309.

20. Pope, R. M., R. S. Wallis, D. Sailer, T. M. Buchanan, and M. A. Pahlavani. 1991. T cell activation by mycobacterial antigens in inflammatory synovitis. Cell. Immunol. 133:95-108.

21. Holoshitz, J., F. Koning, J. E. Coligan, J. De Bruyn, and S. Strober. 1989. Isolation of CD4-CD8-mycobacteria-reactive $T$ lymphocyte clones from rheumatoid arthritis synovial fluid. Nature (Lond.). 339:226-229.

22. Holoshitz, J., N. C. Romzek, Y. Jia, L. Wagner, L. M. Vila, S. Chen, J. M. Wilson, and D. R. Karp. 1993. MHC-independent presentation of mycobacteria to human $\gamma \delta$ T cells. Int. Immunol. 5:1437-1443.

23. Holoshitz, J., L. M. Vila, B. J. Keroack, D. R. McKinley, and N. K. Bayne. 1992. Dual antigenic recognition by cloned human $\gamma \delta \mathrm{T}$ cells. J. Clin. Invest. 89:308-314.

24. Strahler, J. R., R. Kuick, and S. M. Hanash. 1989. Two-dimensional polyacrylamide gel electrophoresis of proteins. In Protein Structure: A Practical Approach. T. E. Creighton, editor. IRL Press, Oxford. 65-92.

25. Merril, C. R., D. Goldman, S. A. Sedman, and M. H. Ebert. 1981. Ultrasensitive stain for proteins in polyacrylamide gels shows regional variation in cerebrospinal fluid proteins. Science (Wash. DC). 211:1437-1438.

26. Kuick, R. D., S. M. Hanash, E. H. Y. Chu, and J. R. Strahler. 1987. A comparison of some adjustment techniques for use with quantitative spot data from two-dimensional gels. Electrophoresis. 8:199-204.

27. Keim, D., N. Hailat, D. Hodge, and S. M. Hanash. 1990. Proliferating cell nuclear antigen expression in childhood acute leukemia. Blood. 76:985-990.

28. Johnston, R. F., S. C. Pickett, and D. L. Barker. 1990. Autoradiography using storage phosphor technology. Electrophoresis. 11:355-360.

29. Bravo, R., J. Bellatin, and J. E. Celis. 1981. $\left[{ }^{35}\right.$ S ] Methionine labeled polypeptides from HeLa cells, coordinates and percentage of some major polypeptides. Cell Biol. Int. Rep. 5:93-96.

30. Towbin, H., T. Staehelin, and J. Gordon. 1979. Electrophoretic transfer of proteins from polyacrylamide gels to nitrocellulose sheets: procedure and some applications. Proc. Natl. Acad. Sci. USA. 76:4350-4354.

31. Thomas, P. S. 1980. Hybridization of denatured RNA and small DNA fragments transferred to nitrocellulose. Proc. Natl. Acad. Sci. USA. 77:52015205.

32. Chomczynski, P., and N. Sacchi. 1987. Single-step method of RNA isolation by acid guanidinium thiocyanate-phenol-chloroform extraction. Anal. Biochem. 162:156-159.

33. Almendral, J. M., D. Huebsch, P. A. Blundell, H. MacDonald-Bravo, and R. Bravo. 1987. Cloning and sequence of the human nuclear protein cyclin: homology with DNA-binding proteins. Proc. Natl. Acad. Sci. USA. 84:15751579.

34. Shipman-Appasamy, P., K. S. Cohen, and M. B. Prystowsky. 1990. Interleukin 2-induced expression of proliferating cell nuclear antigen is regulated by transcriptional and post-transcriptional mechanisms. J. Biol. Chem. 265:1918019184.

35. Alder, H., M. Yoshinouchi, M. B. Prystowsky, P. Appasamy, and R. Baserga. 1992. A conserved region in intron 1 negatively regulates the expression of the PCNA gene. Nucleic Acids Res. 20:1769-1775.

36. Chang, C. D., L. Ottavio, S. Travali, K. E. Lipson, and R. Baserga. 1990. Transcriptional and posttranscriptional regulation of the proliferating cell nuclear antigen gene. Mol. Cell. Biol. 10:3289-3296.

37. Matsumoto, K., T. Moriuchi, T. Koji, and P. K. Nakane. 1987. Molecular cloning of cDNA coding for rat proliferating cell nuclear antigen (PCNA)/cyclin. EMBO (Eur. Mol. Biol. Organ.) J. 6:637-642.

38. Kurki, P., M. Lotz, K. Ogata, and E. M. Tan. 1987. Proliferating cell nuclear antigen (PCNA)/cyclin in activated human T lymphocytes. J. Immunol. 138:4114-4120.

39. Monaghan, P., N. P. Perusinghe, R. I. Nicholson, R. A. McClelland, M. J. O'Hare, D. P. Lane, H. Jayatilake, and B. A. Gusterson. 1991. Growth factor stimulation of proliferating cell nuclear antigen (PCNA) in human breast epithelium in organ culture. Cell Biol. Int. Rep. 15:561-570.

40. Bravo, R., and H. MacDonald-Bravo. 1984. Induction of the nuclear protein 'cyclin' in quiescent mouse 3T3 cells stimulated by serum and growth factors. Correlation with DNA synthesis. EMBO (Eur. Mol. Biol. Organ.) J. 3:3177-3181.

41. Sabath, D. E., D. S. Monos, S. C. Lee, C. Deutsch, and M. B. Prystowsky. 1986. Cloned T-cell proliferation and synthesis of specific proteins are inhibited by quinine. Proc. Natl. Acad. Sci. USA. 83:4739-4743.

42. Pfeffer, K., B. Schoel, H. Gulle, S. H. E. Kaufmann, and H. Wagner. 1990. Primary responses of human $\mathrm{T}$ cells to mycobacteria: a frequent set of $\gamma / \delta \mathrm{T}$ cells are stimulated by protease-resistant ligands. Eur. J. Immunol. 124:1175-1179.

43. Pfeffer, K., B. Schoel, N. Plesnila, G. B. Lipford, S. Kromer, K. Deusch, and H. Wagner. 1992. A lectin-binding protease-resistant mycobacterial ligand specifically activates $\mathrm{V}_{\gamma} 9^{+}$human $\gamma \delta \mathrm{T}$ cells. J. Immunol. 148:575-583.

44. Kurki, P., M. Vanderlann, F. Dolbeare, J. Gray, and E. M. Tan. 1986 Expression of proliferating cell nuclear antigen (PCNA)/cyclin during the cell cycle. Exp. Cell Res. 166:209-219.

45. Bravo, R., and J. E. Celis. 1980. A search for differential polypeptide synthesis throughout the cell cycle of HeLa cells. J. Cell Biol. 84:795-802.

46. Morris, G. F., and M. B. Mathews. 1989. Regulation of proliferating cell nuclear antigen during the cell cycle. J. Biol. Chem. 264:13856-13864.

47. Bravo, R., and H. MacDonald-Bravo. 1985. Changes in the nuclear distribution of cyclin (PCNA) but not its synthesis depend on DNA replication. EMBO (Eur. Mol. Biol. Organ.) J. 4:655-661.

48. Weinberg, D. H., and T. J. Kelly. 1989. Requirement for two DNA polymerases in the replication of simian virus 40 DNA in vitro. Proc. Natl. Acad. Sci. USA. 86:9742-9746.

49. MacDonald-Bravo, H., and R. Bravo. 1985. Induction of the nuclear protein cyclin in serum-stimulated quiescent 3 T3 cells is independent of DNA synthesis. Exp. Cell Res. 156:455-461.

50. Turka, L. A., J. Gratiot-Deans, D. Keim, R. Bandukwala, J. Green, J. Strahler, and S. M. Hanash. 1993. Elevated proliferating cell nuclear antigen levels in immature thymocytes: dissociation from cell cycle progression. J. Immunol. $150: 2746-2752$. 